\title{
THE ORIGIN OF LIFE
}

\author{
N. H. Horowitz and Jerry S. Hubbard ${ }^{1}$ \\ Biology Division, California Institute of Technology, Pasadena, California 91109
}

\section{INTRODUCTION}

The origin of life is in a sense a genetic problem, for, as $\mathbf{H}$. J. Muller pointed out many years ago, the essential attribute that identifies living matter is its capacity to replicate itself and its variants (1). Because this uniquely biological property has its physical basis in proteins and nucleic acids, the goal of modern work on the origin of life is to discover the manner of origin of these polymers and of the interactions between them that constitute the genetic mechanism. In attempting to review this subject in a limited space, we cannot undertake an exhaustive treatment. Rather, we summarize work published principally since 1970 in the following areas, with emphasis on those aspects that are of greatest current interest: 1. precambrian paleontology, 2. chemical evolution of genetically important monomers, 3. prebiotic dehydration-condensation reactions, 4 . organic compounds in meteorites and interstellar space, and 5. biological exploration of the planets.

A large number of review articles (2-5), critical and theoretical discussions (6-8), books (9-16), and conference proceedings (17-21) dealing with the origin of life have appeared in recent years. In addition, a new serial, the Journal of Molecular Evolution, publishing papers on this and related subjects, appeared in 1971; the journal Space Life Sciences has been renamed Origins of Life; and a society, the International Society for the Study of the Origin of Life, was recently founded.

\section{PRECAMBRIAN PALEONTOLOGY}

Until about 20 years ago it was thought that no fossils remained of the life that populated the earth before the opening of the Cambrian era 600 million years ago. For the first $85 \%$ of Earth's history there were thus no data on which estimates of the rate of evolution and the epoch of the origin of life might be based. The situation has changed with the discovery of a dozen or more Precambrian sediments, some of them exceeding $3 \times 10^{9}$ years in age, containing a variety of fossilized microorganisms. These findings have been reviewed by Schopf (22).

${ }^{1}$ Present address: School of Biology, Georgia Institute of Technology, Atlanta, Georgia 30332. 
The oldest objects generally accepted as fossils at the present time are unicellular organisms resembling bacteria and coccoid blue-green algae, found in cherts of the Fig Tree Series of South Africa $(23,24)$. These cherts have been dated at $3.1 \times 10^{9}$ years. A still older series of rocks of the same general sequence, the Onverwacht Group, with an age of approximately $3.3 \times 10^{9}$ years (25), contains microstructures that have been interpreted with varying degrees of confidence as fossils (26-29). The Onverwacht structures are more variable in size and, if fossils, are also less well preserved than those of the Fig Tree sediments.

Fossil identifications in these ancient rocks are based on morphology (including its continuity with that of better-preserved and more abundant fossils in younger sediments) and on the organic chemistry of the host rock. Precambrian cherts typically contain $0.5-1.0 \%$ organic matter, the bulk of it in the form of an insoluble, unextractable polymer ("kerogen"). Most of the chemical work has naturally been done on the small extractable fraction. This has been found to contain a characteristically biological assemblage of hydrocarbons, including pristane and phytane (known breakdown products of chlorophyll), and amino acids. Recent work has cast doubt on the significance of these findings, because it appears that the soluble fraction may not be syngenetic with the rocks. Various types of evidence indicate that the cherts are sufficiently permeable to have been infiltrated by soluble material over geologic time and that the soluble fraction is largely or entirely of recent origin (30-33).

Similar doubts have not arisen with regard to the insoluble fraction which, being less mobile, is more likely to be indigenous to the rocks. Pyrolytic analysis shows that this fraction consists mainly of polymerized aliphatic and aromatic hydrocarbons $(34,35)$. Carbon isotope ratios of kerogens from the Fig Tree and upper Onverwacht sediments show the deficiency of ${ }^{13} \mathrm{C}$ that is typical of photosynthetically derived organic matter $(32,36)$ and thus support the morphological evidence which suggests that blue-green alga-like forms were extant in Fig Tree times. The carbon from lower Onverwacht kerogens is anomalously heavy, however, a finding that led Oehler et al to speculate that an unusual geological or biological event, such as the onset of photosynthesis or even the origin of life, occurred in Onverwacht times (36). The heavy kerogen, it was suggested, may be left over from a prephotosynthetic or prebiotic era. This is an extraordinarily interesting result, but, to quote the authors, "the data are so few and their potential implication so far-reaching that no firm conclusion should be drawn at the present time."

Whatever the outcome of this issue, it seems established that life existed on the earth $3.1 \times 10^{9}$ years ago, and it appears that at least one species was carrying out photosynthesis at that time. Because the capacity for photosynthesis represents a long evolutionary development from the presumed heterotrophy of the primordial organism, the implication is that life originated at a much earlier time, possibly during the first billion years of the earth's 4.5 billion year history.

Evidence is beginning to accumulate on the time of origin of the eukaryotic cell. Eukaryotic cells seem to be well established in the Bitter Springs Formation of Australia, about 900 million years old (22), but the remains of possibly nuclear structures have been discovered in the much older Beck Spring dolomite of Califor- 
nia, estimated to be $1.3 \times 10^{9}$ years of age (37). Recent findings of relatively complex multicellular microfossils in the McArthur Group formation of Australia, thought to be $1.6 \times 10^{9}$ years of age, suggest that eukaryotic organisms may have existed at this even earlier time (38).

\section{CHEMICAL EVOLUTION OF GENETICALLY IMPORTANT MONOMERS}

The synthesis of amino acids, purines, pyrimidines, and sugars from cosmically abundant gases has been demonstrated in numerous investigations since Stanley Miller (39) performed the first experiments in this field (see 3, 10,11, 15 for reviews of these investigations). It is clear that there are many pathways from primitive gas mixtures to the genetically important monomers, and it is unlikely that any one pathway was exclusively involved in their synthesis on the primitive earth. Recent work in this area is concerned with the investigation of various alternative prebiotic conditions, energy sources, and starting materials (reviewed below) and with the study of some particularly difficult syntheses, e.g. methionine (40), thymine (41), and aromatic amino acids (42).

\section{Long-Wavelength uv as Energy Source}

Although the original Miller experiment used a spark discharge as energy source, solar radiation is now and probably was in primitive times the major source of energy reaching the earth $(6,43)$. However, only a small fraction of sunlight is in wavelengths below $200 \mathrm{~nm}$ where $\mathrm{CH}_{4}, \mathrm{CO}, \mathrm{NH}_{3}, \mathrm{~N}_{2}, \mathrm{H}_{2} \mathrm{O}$, and $\mathrm{H}_{2}$ have almost their entire absorption. The large amount of energetic radiation between 200 and $300 \mathrm{~nm}$ is photochemically useless in these gases without a photosensitizing agent that can absorb and transfer energy in this spectral range. $\mathrm{Hg}$ vapor is such an agent (44), but it is not a plausible constituent of the primitive atmosphere.

Sagan \& Khare (45) have found that $\mathrm{H}_{2} \mathrm{~S}$, which absorbs in the $200-300 \mathrm{~nm}$ region, photosensitizes the synthesis of glycine, alanine, serine, glutamic acid, aspartic acid, and cystine, together with an orange-brown polymer, from mixtures of $\mathrm{CH}_{4}, \mathrm{C}_{2} \mathrm{H}_{6}, \mathrm{NH}_{3}$, and $\mathrm{H}_{2} \mathrm{O}$ irradiated with the $254 \mathrm{~nm}$ line of a $\mathrm{Hg}$ source. Ethane was essential, for reasons that are not understood. Ethane would occur only in traces in a reducing atmosphere at equilibrium. It can be generated from methane by electric discharges or short uv, but these are the energy sources for which the experiment is seeking an alternative. Similarly, the partial pressure of $\mathrm{H}_{2} \mathrm{~S}$ in the primitive atmosphere would have been limited by the formation of metal sulfides on the earth's surface and by photolysis in the atmosphere (46).

In similar experiments with $\mathrm{H}_{2} \mathrm{~S}$, Becker and co-workers have confirmed the production of amino acids, but without formation of the orange polymer (47). Most important, these workers did not find a requirement for $\mathrm{C}_{2} \mathrm{H}_{6} . \mathrm{CH}_{4}$ was sufficient as a carbon source to produce amino acids. The quantum yields calculated by the two groups of experimenters are comparable: $10^{-4}-10^{-5}$. No explanation has been established for the discrepancy in results. If $\mathrm{CH}_{4}$ in fact suffices for amino acid 
production, this reaction may have been an important primary source of biomonomers on the primitive earth.

\section{Acoustic Energy}

It is known from the work of Elpiner (48) that ultrasonic vibrations can produce organic compounds, including $\mathrm{HCN}$ and $\mathrm{HCHO}$, in water saturated with $\mathrm{N}_{2}, \mathrm{CO}$ (or $\mathrm{CH}_{4}$ ), and $\mathrm{H}_{2}$. The reactions occur in cavitation bubbles which, on collapsing, generate intense hydraulic shocks accompanied by brief but very high pressure and temperature pulses. Anbar (49) showed that cavitation occurs in systems simulating ocean waves and falling water; amino acids were produced when the water contained $\mathrm{NH}_{3}$ and $\mathrm{CH}_{4}$. Recently Bar-Nun et al found that amino acids are synthesized in gas mixtures by shock waves simulating the entry of meteorites into the atmosphere (50). The efficiency was extraordinarily high: $5 \times 10^{10}$ molecules of amino acid per erg of shock energy. The authors estimate that $30 \mathrm{~kg}$ of organic matter per $\mathrm{cm}^{2}$ of the earth's surface could have been produced in the first $10^{9}$ years of the earth's history by meteorite- and thunder-induced shock waves. Unfortunately, the gas mixture used in the experiments of Bar-Nun et al contained ethane, so that it is difficult to evaluate the significance of the high efficiency they observed.

\section{CO as a Carbon Source}

The ocean and atmosphere were produced by outgassing from the molten interior of the earth. $\mathrm{CO}$ is stable at magmatic temperatures and would have been the principal form of outgassed carbon. Methane is the stable form of carbon in a reducing atmosphere at low temperatures, however, and would have formed slowly from $\mathrm{CO}$ on cooling. A continuing output of $\mathrm{CO}$ from volcanoes would have maintained a steady-state pressure of $\mathrm{CO}$ in the primitive atmosphere [see Abelson (51) and Van Trump \& Miller (52) for further discussion]. CO is also a constituent of the Martian atmosphere, and it is a major component of interstellar clouds (see section on organic compounds in meteorites and interstellar space, p. 402).

The reduction of $\mathrm{CO}$ by $\mathrm{H}_{2}$ is accelerated by various metallic catalysts, this being the basis of the Fischer-Tropsch process for making hydrocarbons. Anders and co-workers (53) have proposed that a Fischer-Tropsch-like reaction in which $\mathrm{NH}_{3}$ participates along with $\mathrm{CO}$ and $\mathrm{H}_{2}$ can account more satisfactorily than can the Miller-Urey reaction for some prebiotic syntheses. (Fischer-Tropsch-like reactions are discussed further on pp. 402-3.)

A different type of surface-catalyzed reaction involving $\mathrm{CO}$ has been discovered by Hubbard et al in experiments designed initially to simulate the surface environment of Mars $(54,55)$. It was found that uv irradiation of siliceous materials or alumina in atmospheres containing $\mathrm{CO}$ and water vapor (diluted in a large volume of $\mathrm{CO}_{2}$ or $\mathrm{N}_{2}$ ) results in the synthesis of simple organic compounds on the solid surfaces. The major product is formic acid, with smaller amounts of formaldehyde, acetaldehyde, and glycolic acid. The most remarkable feature of this reaction is that it is effected by wavelengths as long as $300 \mathrm{~nm}$, although the gaseous reactants do 
not absorb wavelengths longer than $200 \mathrm{~nm}$. Photosensitization is provided by the solid surfaces, which also protect the photosensitive products from destruction by uv. The available evidence suggests that the reaction is initiated by absorption of the excitation energy by the solid substratum with cleavage of silanol ( $\mathrm{Si}-\mathrm{OH}$ ) bonds in the case of siliceous substrata to form surface $\mathrm{OH}$ radicals (56). Reaction of the $\mathrm{OH}$ radical with $\mathrm{CO}$ could yield surface $\mathrm{COOH}$ radicals, the precursor of formic acid.

On highly effective substrata such as volcanic ash shale or clay minerals, this photocatalysis can produce tens of nanomoles of product per $\mathrm{cm}^{3}$ per day (55). Photodestruction of the organic products occurs, as well as synthesis, and eventually a steady state is attained in which the rates of formation and decomposition are equal.

If $\mathrm{NH}_{3}$ is added to the above system, urea, formamide, and formaldehyde are produced photocatalytically from $\mathrm{CO}$ and $\mathrm{NH}_{3}$ (57). This reaction apparently depends on the formation of a complex between $\mathrm{NH}_{3}$ and the surface material which absorbs at longer wavelengths than does free $\mathrm{NH}_{3}$. Because the reaction between $\mathrm{CO}$ and $\mathrm{NH}_{3}$ is inhibited by water vapor, its relevance for terrestrial chemistry is questionable, but it may offer a mechanism for the synthesis of interstellar molecules on siliceous grains (see p. 402).

\section{Stability of Ammonia in the Primitive Atmosphere}

$\mathrm{NH}_{3}$ is the thermodynamically favored form of nitrogen in a reducing atmosphere at ordinary temperatures (43). The lack of an ozone screen in such an atmosphere would, however, permit rapid photolysis of $\mathrm{NH}_{3}$ (to $\mathrm{N}_{2}+\mathrm{H}_{2}$ ) by uv wavelengths shorter than $230 \mathrm{~nm}$ (51). The question of the actual lifetime of $\mathrm{NH}_{3}$ in the primitive atmosphere is thus of interest. Some years ago, Bada \& Miller (58) made an ingenious estimate of the lower limit of $\mathrm{NH}_{4}^{+}$in the primitive ocean based on the fact that $\mathrm{NH}_{4}^{+}$is necessary to prevent the deamination of aspartate in solution. This estimate, about $10^{-3} \mathrm{M}$, leads to a minimum pressure of about $10^{-6}$ atm $\mathrm{NH}_{3}$ in the atmosphere. In recent theoretical studies, Ferris \& Nicodem $(46,59)$ find that photolysis of $\mathrm{NH}_{3}$ is so rapid that its lifetime would not have exceeded a few millions of years under conditions usually considered realistic for the primitive earth. The presence of $\mathrm{H}_{2}$ at high pressure ( $>50$ torr) could have maintained $\mathrm{NH}_{3}$ by regenerating it, as could the slow release of $\mathrm{NH}_{3}$ by the hydrolysis of urea formed from $\mathrm{NH}_{3}$ and $\mathrm{CO}$. In the absence of these mechanisms, it appears that either $\mathrm{NH}_{3}$ had no role in the origin of life, or its role was completed within the first few million years of the earth's history.

\section{PREBIOTIC DEHYDRATION-CONDENSATION REACTIONS}

The condensation of amino acids into polypeptides and of bases, sugars, and phosphate into mono- and polynucleotides involves dehydrations that are endergonic by 2-6 kcal per mole. Attempts to find plausible prebiotic mechanisms for these energyconsuming reactions have been carried out under three principal conditions: homogeneous aqueous, heterogeneous aqueous, and nonaqueous thermal. 


\section{Homogeneous Aqueous Dehydrations}

A number of simple derivatives of $\mathrm{HCN}$ have been found to promote dehydrationcondensations in aqueous solution, e.g. cyanamide, cyanogen, cyanamide dimer, and others $(3,10,11)$. These compounds are energy-rich with respect to their hydration products. They add water in reactions similar to those entered into by carbodiimides in synthetic organic chemistry:

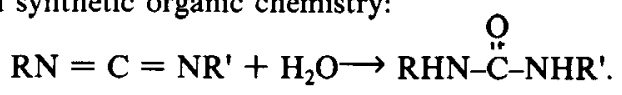

Although a variety of $\mathrm{HCN}$ derivatives may well have existed on the primitive earth, their importance for prebiological dehydration reactions is questionable because of the fact that that they react readily with solvent water. (In synthetic chemistry, carbodiimides are used in anhydrous solvents.) Because of this lack of specificity, very high concentrations of $\mathrm{HCN}$ derivatives are needed to bring about significant peptide- and ester-bond formation in aqueous solution. A critical review of these findings, with a bibliography of important papers, is given by Miller \& Orgel (15).

Alkaline solutions of $\mathrm{HCN}$ form, on standing, an insoluble black material referred to as "polymer." Acid hydrolysis of the colored supernatant from these preparations yields a complex mixture of ninhydrin-positive substances, including amino acids (60). Matthews and co-workers (61 and earlier papers cited there) have proposed that $\mathrm{HCN}$ polymer is a polypeptide formed directly from $\mathrm{HCN}$ and water without the intervention of free amino acids. On this view, the manner of formation and polymerization of amino acids is irrelevant to the question of the origin of proteins. Ferris et al (62) find, however, that amino acids are not released from $\mathrm{HCN}$ polymer by proteolytic enzymes, nor can a dinitrophenyl derivative or a positive biuret reaction be elicited. It is difficult to reconcile these results with a peptidic structure. It appears that the numerous products derivable from $\mathrm{HCN}$ polymer are formed by hydrolysis and/or oxidation-reduction of an equilibrium mixture of $\mathrm{HCN}$ and its dimer, trimer, and tetramer that forms spontaneously in alkaline HCN solutions (63).

\section{Heterogeneous Aqueous Dehydrations}

One of J. D. Bernal's principal contributions to the study of chemical evolution was the idea that dilute solutions of biomonomers in the primitive ocean could have been concentrated by adsorption on the surface of clay minerals, or at air-water interfaces, where further reactions among them might take place $(9,64)$. Until now, the best example of such a process has been the polymerization of alanyl adenylate to polyalanine on the surface of montmorillonite, discovered by Paecht-Horowitz et al (65). Aminoacyl adenylates react in free solution to yield short peptide chains and adenylic acid, but hydrolysis to monomeric amino acid predominates. In the presence of montmorillonite, a common aluminosilicate clay mineral having a layerlattice structure and a large absorptive capacity, the predominant reaction is polymerization. Polymers containing up to 56 alanyl residues are formed in $24 \mathrm{hr}$ under mild conditions.

In a recent paper, the same authors have taken the process a step further by showing that the synthesis of alanyl adenylate from alanine and ATP is catalyzed 
by a synthetic zeolite (66). In a system containing alanine, ATP, zeolite, and montmorillonite, the amino acid is polymerized quantitatively. It is doubtful whether ATP in large amounts was available in prebiological times, although small quantities were probably produced by reactions described below. It would be interesting to know whether polyphosphates, energetically equivalent to ATP and possibly more abundant on the primitive earth, can serve as the energy source for this remarkable polymerization.

It has recently been claimed that kaolinite has the property of adsorbing amino acids from dilute solutions at $90^{\circ} \mathrm{C}$ and polymerizing them to polypeptides, with a strong preference for the $\mathrm{L}$-optical isomers $(67,68)$. Bonner \& Flores $(69,70)$ have tried unsuccessfully to repeat these observations; they could find evidence neither for asymmetric adsorption of amino acids nor for polymerization. Along similar lines, Amariglio \& Amariglio (71) have summarized their careful attempts to duplicate experiments claiming to demonstrate optical asymmetry in reactions catalyzed by optically active quartz. The results were uniformly negative. The most reasonable explanation for the optical asymmetry of living matter is that it is a biologically determined property which has selective value, but the choice of optical isomers was originally a matter of chance. Wald advanced this view many years ago (72).

\section{Nonaqueous Thermal Dehydrations}

The energy requirement for dehydration condensations can be reduced by carrying the reactions out under anhydrous conditions. S. W. Fox discovered some years ago that dry amino acid mixtures heated to $150^{\circ} \mathrm{C}$ or higher condense to form polypeptides if the mixture contains sufficiently large amounts of glutamic or aspartic acid, or lysine. The properties of these thermal polypeptides have been the subject of a large number of investigations by Fox and his associates, who have based a theory of the origin of life on them (14). That the thermal polymerization of amino acids played an important role in chemical evolution has been questioned on two grounds: First, amino acids and polypeptides are unstable at $150-200^{\circ} \mathrm{C}$, except for brief exposures. It is difficult to see how a correctly timed exposure to such a temperature - long enough to effect the reaction, but not so long as to destroy the productscould have been attained on a large scale under natural conditions. Second, it is doubtful whether mixtures of pure amino acids like those used in these experiments ever existed on the primitive earth. Yet it is questionable whether polymerization would occur in a complex and more realistic mixture of organic chemicals, where the growth of peptide chains could be stopped by reactions with a variety of plausible molecules $(9,15,73)$. It should be added that almost all so-called prebiotic syntheses are subject to one or the other of these objections in some degree, but the thermal synthesis of peptides seems particularly vulnerable to them.

Nonaqueous dehydrations that proceed at temperatures below $100^{\circ} \mathrm{C}$ have been described in a number of recent papers. Neuman et al $(74,75)$ find that adenosine is phosphorylated to a mixture of $2^{\prime}, 3^{\prime}$, and $5^{\prime}$-AMPs when heated to $95^{\circ} \mathrm{C}$ with inorganic pyrophosphate and apatite (the generic name for common calcium phosphate minerals). When 5'-AMP was treated in the same way, 5'-ADP and 5'-ATP were identified among the products. Both apatite and pyrophosphate were required for these reactions. 
Orgel and co-workers have found that many nonaqueous dehydrations are catalyzed by simple organic or inorganic substances, of which urea, imidazole, and $\mathrm{Mg}^{2+}$ are particularly effective. Thus, purine and pyrimidine nucleosides are phosphorylated at temperatures of $65-100^{\circ} \mathrm{C}$ in dry mixtures with urea, ammonium chloride, and inorganic phosphate $(76,77)$. Hydroxylapatite can serve as the source of phosphate. Cyclic nucleoside 2', 3'-phosphates and nucleoside 5'-phosphates are formed in good yields in this reaction. If ammonium dihydrogen phosphate is included in the system, oligonucleotides are produced, largely with the biologically important 3'-5' linkage (78). Adenosine cyclic 2', 3'-phosphate polymerizes to oligonucleotides when dried in the presence of diamines (79). Urea and ammonium dihydrogen phosphate heated together form long-chain polyphosphates (80). A large excess of urea is used in these reactions.

The mechanism of the urea-mediated condensations is not clear. Osterberg \& Orgel (80) favor the view that urea acts as an acid-base catalyst. In an earlier study Lundstrom \& Whittaker (81) proposed that urea functions as a dehydrating agent by undergoing hydrolysis to $\mathrm{CO}_{2}$ and $\mathrm{NH}_{3}$. Urea is readily produced from cosmically abundant gases and is a frequently observed product of simulated prebiotic experiments (see 57 and 82 for recent examples).

The addition of $\mathrm{Mg}^{2+}$ to the ammonium phosphate-urea system causes the precipitation of $\mathrm{MgNH}_{4} \mathrm{PO}_{4} \cdot 6 \mathrm{H}_{2} \mathrm{O}$, or struvite, a mineral that may have precipitated from the primeval ocean (83-85). When nucleotides are heated with struvite and urea at $65-100^{\circ} \mathrm{C}$, nucleoside-5'-diphosphates are formed in good yield, with small amounts of nucleoside triphosphates (86). $\mathrm{Mg}$ salts are also involved in dry-phase syntheses of purine nucleosides from ribose and base discovered by Fuller et al (87); one of these is catalyzed by sea salts (88).

In a recent note (89), Lohrmann \& Orgel report that $\mathrm{Mg}^{+}$catalyzes the reaction, in the dry state, of ATP with imidazole to form adenosine-5'-phosphorimidazolide (ImpA). The latter had been shown previously to condense to short oligonucleotides on a poly-U template (90). It is now found that ImpA heated with glycine generates oligopeptides. The synthesis of short peptides is accomplished in one operation by heating ATP, glycine, imidazole, and $\mathrm{Mg}^{2+}$ together. The authors propose a general scheme for the prebiotic synthesis of oligonucleotides and oligopeptides based on $\mathrm{Mg}^{2+}$-, urea-, and imidazole-catalyzed reactions. Several syntheses of imidazole from simple precursors are known (see 89 for references).

\section{ORGANIC COMPOUNDS IN METEORITES AND INTERSTELLAR SPACE}

\section{Amino Acids in Meteorites}

Before 1970, little significance was attached to findings of amino acids and other compounds of biological interest in meteorites, because it was difficult to distinguish between indigenous compounds and contaminants acquired during entry of the meteorite into the earth's atmosphere, impact with the ground, and subsequent handling, storage, and processing for analysis. The early findings have been reviewed elsewhere (91). The situation has changed in recent years as a result of the develop- 
ment of ultrasensitive analytical methods based on combined gas chromatography and mass spectrometry (GCMS), which can not only identify individual amino acids present in meteorites, but in addition determine their optical purity. Also important has been recognition of the need for rapid recovery of observed meteorite falls and their handling and storage under chemically clean conditions.

Only a minor fraction of recovered meteorites (the carbonaceous chondrites) contains organic carbon, and not all of these have sufficient nitrogen to yield detectable amino acids. Of particular interest in recent years has been the Murchison meteorite, a carbonaceous chondrite that fell near Murchison, Australia in September 1969 . This meteorite contains $2 \%$ carbon and $0.16 \%$ nitrogen (92). Much of the organic carbon is present as a complex mixture of aliphatic and aromatic hydrocarbons $(92,94)$. Carbon isotope analysis indicates that this material has a nonbiological source (92).

Water extraction of the meteorite followed by $\mathrm{HCl}$ hydrolysis yields a fraction containing about $20 \mu \mathrm{g}$ of amino acids per gram of meteorite. Analysis by GCMS of the $\mathrm{N}$-trifluoroacetyl-D-2-butyl esters (a derivative that volatilizes amino acids and converts enantiomers into diastereoisomers with chemically distinguishable properties) revealed 18 amino acids, of which 6 were identified as "normal" protein amino acids (glycine, alanine, valine, proline, glutamic and aspartic acids) and 12 were nonprotein amino acids $(92,93)$. All of the amino acids with asymmetric carbon atoms whose diastereoisomers could be resolved ( 9 out of 18) were found in nearly racemic mixtures. These findings by Kvenvolden et al have been confirmed by a different approach in which amino acid enantiomers were separated on optically active columns in a GCMS procedure (94). The results clearly indicate a nonbiological and extraterrestrial origin of meteoritic amino acids, because terrestrial contamination would introduce predominantly optically active amino acids of the kinds found in proteins.

Almost identical results have been obtained with the Murray chondrite which fell in the US in $1950(95,96)$. It has also been possible by the GCMS method to demonstrate the presence of nonprotein amino acids, at least one of them racemic, in the Orgueil meteorite (97). This carbonaceous chondrite, one of the most famous in the world, fell in France in 1864 and has been extensively studied. Pasteur is said to have examined it for bacteria, with negative results (98). Because it is heavily contaminated, it has not been possible until now to establish that some of its amino acids are indigenous to the meteorite.

It is the usual practice to hydrolyze the aqueous extracts to maximize the yield of amino acids. It has been shown, however, that free amino acids are present in unhydrolyzed extracts of Murchison and Murray, although in substantially lower amounts than in hydrolyzed samples (96). The nature of the hydrolyzable precursor is uncertain.

\section{Purines and Pyrimidines in Meteorites}

The heterocyclic bases of meteorites have received less attention than the amino acids. Hayatsu found evidence for adenine and guanine in the Orgueil (99), but analyses on the Murchison meteorite, known not to be seriously contaminated, are 
more convincing. Folsome et al (100) found 4-hydroxypyrimidine and two of its methylated derivatives in Murchison, but no purines. However, in a preliminary report Anders et al have detected both adenine and guanine in Murchison (53). These authors suggest that the discrepancy between their results and those of Folsome et al may be attributable to different extraction procedures. This important result needs confirmation.

\section{Interstellar Molecules}

In recent years, radioastronomers employing microwave spectroscopy have discovered a large number of molecules of biological importance in interstellar space (reviewed in 101, 102). These molecules are found in association with dust clouds that occur in different regions of the sky, notably in the direction of the great nebula in Orion. It is generally supposed that the dust grains have a catalytic role in the formation of the molecules from the rarefied interstellar gas, and it is certain that they shield them from photolysis by stellar ultraviolet radiation. Since there is reason to think that dust clouds are regions where stars and planetary systems form, the detection in them of molecules that have been identified in laboratory experiments as likely evolutionary precursors of amino acids and nucleotides is a matter of unusual interest.

Of approximately 27 molecules that have been identified in interstellar clouds, the following are of particular biological significance: $\mathrm{H}_{2}, \mathrm{H}_{2} \mathrm{O}, \mathrm{NH}_{3}, \mathrm{H}_{2} \mathrm{~S}, \mathrm{CO}, \mathrm{HCN}$, cyanoacetylene, methanol, formaldehyde, formic acid, formamide, acetonitrile, and acetaldehyde. All of these molecules were identified by microwave spectroscopy except $\mathrm{H}_{2}$, which was found by optical astronomy. As Oró has pointed out (103), this list includes what are generally considered to be the most important prebiotic precursors of amino acids, purines, pyrimidines, and sugars.

\section{General Implications}

The remarkable discoveries summarized above constitute the most important advance of recent years in the study of the origin of life. They show that carbon chemistry very similar to that found in laboratory simulations of the prebiotic earth occurs on a large scale in our galaxy. HCN and cyanoacetylene, for example, are the most abundant primary N-containing products of the Miller spark-discharge experiment $(104,105)$. Aldehydes are also formed in the spark and react with $\mathrm{HCN}$ and $\mathrm{NH}_{3}$ to yield amino acids in a Strecker synthesis (104). $\mathrm{HCN}$ and cyanoacetylene are the starting points for syntheses of adenine $(106,107)$ and cytosine $(105$, 108), respectively. Miller and his associates have shown that all of the amino acids found (and some not found) in the Murchison and Murray meteorites are synthesized in a spark-discharge experiment that differs from the classical Miller experiment in that most of the $\mathrm{NH}_{3}$ is replaced by $\mathrm{N}_{2}(109,110)$. Aminonitriles are produced, and these must be hydrolyzed at the end of the run to yield amino acids; in the original Miller reaction, conditions were sufficiently alkaline to hydrolyze the aminonitriles directly.

An alternative route for the synthesis of organic compounds of meteorites, interstellar clouds, and the primitive earth has been proposed by Anders et al, e.g. 
Fischer-Tropsch-like reactions of $\mathrm{CO}, \mathrm{H}_{2}$, and $\mathrm{NH}_{3}$ (53). These reactions take place spontaneously on the surface of catalysts at temperatures below $600^{\circ} \mathrm{K}$. Magnetite, hydrated silicates, and other minerals expected to be cosmically abundant can serve as catalysts. Fischer-Tropsch-like reactions are not as efficient as the Miller synthesis for amino acids, but they appear to be superior in other respects, for example, in purine, pyrimidine, and hydrocarbon syntheses. Critical discussions of the Fischer-Tropsch-like process have been given by Miller \& Orgel (15) and Oró (103).

After $\mathrm{H}_{2}, \mathrm{CO}$ is the most abundant gas in interstellar clouds. It is also plentiful in volcanic gases. It seems clear that both $\mathrm{CO}$ and $\mathrm{CH}_{4}$ can yield biologically important molecules under various plausible conditions, and it is likely that both did so on the primitive earth. A recent discussion of the fate of $\mathrm{CO}$ in the primitive atmosphere is given by van Trump \& Miller (52).

Chemical evidence strongly suggests that carbonaceous chondrites are relatively unaltered condensates from the solar nebula (111). If so, the organic compounds in these objects date back to the time of formation of the solar system and are a record of the carbon chemistry of that era. An apparently similar chemistry, but in a different place and time, is seen in the interstellar dust clouds. Taken in conjunction with the known chemical makeup of terrestrial organisms, these observations suggest that wherever life occurs in the galaxy it will be built out of similar (although not necessarily identical) molecules.

The question of how large a contribution was made by meteorites and interstellar organic matter to the pool of prebiological organic compounds on the earth has been discussed $(112,113)$. It is unlikely to have been more than a minor fraction of the total, because most incoming organic matter would have been pyrolyzed during entry into the earth's atmosphere or on impact with the ground. The bulk of prebiological organic compounds was probably synthesized from methane or $\mathrm{CO}$ outgassed from the interior of the earth.

\section{BIOLOGICAL ASPECTS OF THE PLANETS}

In considering the possibilities for life on other planets, it is assumed that any such life must be based on carbon chemistry (2). The properties of the carbon atom that peculiarly fit it for the construction of living matter have often been remarked (see for example 114). No credible alternative to carbon-based life has yet been proposed. The cosmic abundance of the light elements, including carbon, and of their compounds (reviewed above) adds further weight to this assumption.

If the foregoing postulate is correct, then most of the bodies in the solar system can be eliminated as possible habitats of life on the basis of two corollaries: First, because low molecular weight compounds of carbon are usually volatile, they would be lost from objects that cannot retain an atmosphere. Yet it seems inescapable that such compounds would be produced by or from living systems, would enter the atmosphere, and would in fact have an essential role in the cycling of matter that must occur on any life-bearing planet. It follows that bodies without an atmosphere are unsuitable for life. The second corollary is that planets whose temperatures are 
higher than about $150^{\circ} \mathrm{C}$ are also unsuitable for life, since carbon compounds become unstable (on a geological time scale) at this temperature.

We can say immediately that life is not possible on the moon or most of the other satellites of the solar system, nor on Mercury or the asteroids, because none of these objects has an appreciable atmosphere. In the case of the moon, this conclusion has been verified by direct observation of the Apollo samples. Venus is also excluded as an abode of life because of its high surface temperature-in the neighborhood of $400-500^{\circ} \mathrm{C}$.

\section{Jupiter}

Jupiter has a deep atmosphere and temperatures that range from $150^{\circ} \mathrm{K}$ or less at the visible cloud tops to an estimated $7000^{\circ} \mathrm{K}$ or more at the central core of the planet. The temperature structure of the Jovian atmosphere results from an internal heat source, whose presence is revealed by the fact, confirmed by the Pioneer 10 flyby (115), that Jupiter radiates some 2.5 times more energy than it receives from the sun. The high temperatures required by the currently accepted physical model of the planet exclude the possibility that life, or even organic matter, exists on the surface, if in fact there is a surface.

It has been generally assumed that the high atmosphere of Jupiter provides a favorable environment for the production of organic matter. Not only are solar radiation and reasonable temperatures available, but also the composition of the atmosphere $\left(\mathrm{H}_{2}, \mathrm{CH}_{4}\right.$, and $\mathrm{NH}_{3}$ observed; $\mathrm{H}_{2} \mathrm{O}$ inferred at lower depths) is qualitatively identical to the Urey atmosphere which has been employed in numerous prebiological simulation experiments, starting with that of Miller (39). In experiments designed specifically to simulate Jovian conditions, Woeller \& Ponnamperuma (116) and Sagan \& Khare (117) demonstrated the expected production of biologically interesting compounds, together with colored organic products which they suggested could account for the red, yellow, and brown coloration of Jupiter. In reviewing these and other data, Sagan (118) concludes that "it does not seem at all out of the question that life has originated on Jupiter."

Serious doubts have been raised about the significance of these experiments in a critical review by Lewis \& Prinn (119). These authors make the point that, contrary to the popular view, conditions on Jupiter are exceedingly hostile to the production of organic matter and the origin of life. As a consequence of its thermal structure, the atmosphere is highly convective. (The visible turbulence of the clouds of Jupiter is an indication of this convection.) Any organic compounds formed in the high atmosphere would be transported convectively, in a time that is short relative to chemical evolution, to deep, hot regions where they would be destroyed. Convective mixing does not extend into the topmost part of the atmosphere, above the tropopause, but little organic synthesis can occur here, because the buildup of complex organic molecules is prevented by uv photolysis and by reactions with $\mathbf{H}_{2}$-by far the most abundant gas in the Jovian atmosphere-which tend to reduce all carbon compounds to $\mathrm{CH}_{4}$ and other simple hydrides. Lewis \& Prinn conclude that none of the reported experiments are relevant to conditions on Jupiter. The same general inferences apply to the other Jovian planets: Saturn, Uranus, and Neptune. 


\section{Titan}

We are left with Mars, Pluto, and the larger satellites of the Jovian planets as the surviving candidate habitats of extraterrestrial life in the solar system. Of the objects beyond Mars, Titan, the largest satellite of Saturn, with an atmosphere more massive than that of Mars, is currently the most interesting biologically. Methane was identified years ago as a constituent of Titan's atmosphere. The mean surface temperature of a body of Titan's albedo and distance from the sun is expected to be about $80^{\circ} \mathrm{K}$, or too low for solution chemistry. Recent infrared measurements, however, have suggested the possibility of an atmospheric greenhouse effect which would produce much higher temperatures and allow biologically interesting models of the surface to be considered (120). Serious studies of the physics and chemistry of Titan are still in their early stages. It seems likely that answers to some of the major questions about Titan will be forthcoming in the near future.

A very tenuous atmosphere on Io, the innermost satellite of Jupiter, is implied by recent results from Pioneer 10 (121). The estimated pressure at the surface is $10^{-8}$ to $10^{-10}$ atmospheres.

\section{Mars}

Mars fulfills the minimal conditions for a life-bearing planet, but these are necessary conditions, not sufficient ones. There is no evidence suggesting that Mars is an abode of life. On the contrary, the indications are on the negative side, but not conclusively so. A definitive answer can only be had by placing a probe on the planet. The first US landing on Mars is planned for 1976 with a pair of sophisticated unmanned spacecraft called Viking. The Viking instruments, which are biased toward experiments of biological interest, have been described in an issue of Icarus (122).

The highly successful Mariner 9 orbiter showed Mars to be more active geologically than had previously been supposed. A series of papers comprising a "final" report on the results of the Mariner 9 mission has been published in the Journal of Geophysical Research (123). Insofar as the new data are concerned with biological questions, they relate to the past history of Mars and the possibility that more favorable environmental conditions existed in earlier epochs. Of particular interest is the geological evidence, supported by theoretical computations on secular fluctuations of the obliquity of the planet (124), suggesting periodic climatic changes (125). Depending on the assumptions one makes about the thickness of the frozen volatile deposits in the polar caps, these changes can produce periods of nearly earthlike conditions in the Martian equatorial region (126) or only very slight climatic effects (127).

One of the surprising discoveries of the Mariner 9 photography was that of various meandering, braided, and dendritic features strongly resembling old water courses (128). Liquid water cannot exist on Mars, except in concentrated salt solutions. The vapor pressure of water in the Martian atmosphere is far below the triple point, and the mean surface temperature is only $210^{\circ} \mathrm{K}$, compared with $288^{\circ} \mathrm{K}$ for the earth. Although ice deposits may well underlie the surface, ice can evaporate but cannot melt under present Martian conditions (129). The source of the water that cut the presumed channels (not all observers are agreed on this interpretation 
of the features) is thus a challenging problem. Climatic amelioration, mentioned above, is one possibility. Another is subsurface water in the form of carbon dioxide hydrate, $\mathrm{CO}_{2} \cdot 6 \mathrm{H}_{2} \mathrm{O}$ (130). This compound, a clathrate, dissociates on the release of pressure such as might occur with deep fracturing of the crust.

Mars is probably losing water to space in the form of atomic hydrogen and oxygen (131). Classical escape theory does not explain the loss of $O$ atoms, but a recently discovered nonthermal escape mechanism does (132). Ionized oxygen derived from $\mathrm{H}_{2} \mathrm{O}$ or $\mathrm{CO}_{2}$ can recombine with an electron to yield energetic $\mathrm{O}$ atoms: $\mathrm{O}_{2}{ }^{+}+\mathrm{e}$ $\longrightarrow \mathrm{O}+\mathrm{O}$. These hot atoms can leave Mars if they are moving in the right direction. A similar mechanism operates for nitrogen (133) and may account for the fact that this element has not been detected in the Martian atmosphere (131). This mechanism is not important for the earth because of its stronger gravitational field.

The extreme dryness of Mars and the possibility that the planet has been severely depleted of nitrogen pose difficult problems for a Martian biota. The discovery of abiotic areas in the far less hostile Antarctic desert, where scarcity of water is also the life-limiting factor, has suggested that Martian life could not be built on a terrestrial model (134).

\section{ACKNOWLEDGMENT}

We wish to acknowledge support from the National Aeronautics and Space Administration, research grant NGR 05-002-308.

\section{Literature Cited}

1. Muller, H. J. 1929. The gene as the basis of life. Proc. Int. Congr. Plant Sci. 1:897-921

2. Horowitz, N. H., Drake, F. D., Miller, S. L., Orgel, L. E., Sagan, C. 1970. The origins of life. In Biology and the Future of Man, ed. P. Handler, 163-201. New York: Oxford Univ. Press. 967 pp.

3. Lemmon, R. M. 1970 . Chemical evolution. Chem. Rev. 70:95-109

4. Ponnamperuma, C. 1971. Primordial organic chemistry and the origin of life. Quart. Rev. Biophys. 4:77-106

5. Stephen-Sherwood, E., Oró, J. 1973. Recent syntheses of bioorganic molecules. Space Life Sci. 4:5-31

6. Hulett, H, R. 1969. Limitations on prebiological synthesis. J. Theor. Biol. 24:56-72

7. Eigen, M. 1971. Self-organization of matter and the evolution of biological macromolecules. Naturwissenschaften 58:465-523

8. Black, S. 1973. A theory on the origin of life. Advan. Enzymol. 193-234

9. Bernal, J. D. 1967. The Origin of Life. Cleveland: World Publ. Co. 345 pp.

10. Calvin, M. 1969. Chemical Evolution. New York: Oxford Univ. Press. 278 pp.
11. Kenyon, D. H., Steinman, G. 1969. Biochemical Predestination. New York: McGraw-Hill. 301 pp.

12. Cairns-Smith, A. G. 1971. The Life Puzzle. Edinburgh: Oliver \& Boyd. $165 \mathrm{pp}$.

13. Rutten, M. G. 1971. The Origin of Life by Natural Causes. New York: Elsevier. 420 pp.

14. Fox, S. W., Dose, K. 1972. Molecular Evolution and the Origin of Life. San Francisco: Freeman. 359 pp.

15. Miller, S. L., Orgel, L. E. 1973. The Origins of Life on the Earth. Englewood Cliffs, NJ: Prentice-Hall. 229 pp.

16. Orgel, L. E. 1973. The Origins of Life. New York: Wiley. $237 \mathrm{pp}$.

17. Margulis, L., Ed. 1970. Origins of Life. I. New York: Gordon \& Breach. $376 \mathrm{pp}$.

18. Margulis, L., Ed. 1971. Origins of Life. II. New York: Gordon \& Breach. $238 \mathrm{pp}$.

19. Buvet, R., Ponnamperuma, C., Eds. 1971. Chemical Evolution and the Origin of Life. Amsterdam: North-Holland. $560 \mathrm{pp}$.

20. Kimball, A. P., Oró, J., Eds. 1971. 
Prebiotic and Biochemical Evolution. Amsterdam: North-Holland. $296 \mathrm{pp}$.

21. Margulis, L., Ed. 1973. Origins of Life: Chemistry and Radioastronomy. New York: Springer. 291 pp.

22. Schopf, J. W. 1970. Precambrian microorganisms and evolutionary events prior to the origin of vascular plants. Biol. Rev. 45:319-52

23. Barghoorn, E. S., Schopf, J. W. 1966. Microorganisms three billion years old from the Precambrian of South Africa. Science 152:758-63

24. Schopf, J. W., Barghoorn, E. S. 1967. Alga-like fossils from the early Precambrian of South Africa. Science 156: $508-12$

25. Hurley, P. M., Pinson, W. H., Nagy, B., Teska, T. M. 1972. Ancient age of the middle marker horizon, Onverwacht Group, Swaziland Sequence, South Africa. Earth Planet. Sci. Lett. 14: 360-66

26. Engel, A. E. J. et al 1968. Alga-like forms in Onverwacht Series, South Africa: Oldest recognized lifelike forms on earth. Science 161:1005-8

27. Nagy, B., Nagy, L. A. 1969. Early preCambrian Onverwacht microstructures: possibly the oldest fossils on earth? Nature 223:1226-29

28. Nagy, L. A. 1971. Ellipsoidal microstructures of narrow size range in the oldest known sediments on earth. Grana 11:91-94

29. Brooks, J., Muir, M. D., Shaw, G. 1973. Chemistry and morphology of Precambrian microorganisms. Nature 244: 215-17

30. Abelson, P. H., Hare, P. E. 1968. Recent amino acids in the Gunflint chert. Carnegie Inst. Wash. Yearb. 67:208-10

31. Nagy, B. 1970. Porosity and permeability of the Early Precambrian Onverwacht chert: origin of the hydrocarbon content. Geochim. Cosmochim. Acta 34:525-27

32. Smith, J. W., Schopf, J. W., Kaplan, I. R. 1970. Extractable organic matter in Precambrian cherts. Geochim. Cosmochim. Acta 34:659-75

33. Oró, J., Nakaparksin, S., Lichtenstein, H., Gil-Av, E. 1971. Configuration of amino acids in carbonaceous chondrites and a Pre-Cambrian chert. Nature 230:107-8

34. Simmonds, P. G., Shulman, G. P., Stembridge, C. H. 1969. Organic analysis by pyrolysis-gas chromatographymass spectrometry, a candidate experiment for the biological exploration of
Mars. J. Chromatograph. Sci. 7:36-41

35. Scott, W. M., Modzeleski, V. E., Nagy, B. 1970. Pyrolysis of early pre-Cambrian Onverwacht organic matter $>3$ $\times 10^{9}$ yr old). Nature 225:1129-30

36. Oehler, D. Z., Schopf, J. W., Kvenvolden, K. A. 1972. Carbon isotopic studies of organic matter in Precambrian rocks. Science 175:1246-48

37. Cloud, P. E. Jr., Licari, G. R., Wright, L. A., Troxel, B. W. 1969. Proterozoic eucaryotes from eastern California. Proc. Nat. Acad. Sci. USA 62:623-30

38. Muir, M. D. 1973. Microfossils from the Middle Precambrian McArthur Group, Northern Territory. Presented at 4th Int. Conf. Origin of Life, Barcelona

39. Miller, S. L. 1953. A production of amino acids under possible primitive earth conditions. Science 117:528-29

40. van Trump, J. E., Miller, S. L. 1972. Prebiotic synthesis of methionine. Science 178:859-60

41. Stephen-Sherwood, E., Oró, J., Kim. ball, A. P. 1971. Thymine: a possible prebiotic synthesis. Science 173:446-47

42. Friedmann, N., Haverland, W. J., Miller, S. L. 1971. Prebiotic synthesis of the aromatic and other amino acids. See Ref. 19 , pp. 123-35

43. Miller, S. L., Urey, H. C. 1959. Organic compound synthesis on the primitive earth. Science 130:245-51

44. Groth, W. 1957. Photochemische Bildung von Aminosäuren und anderen organischen Verbindungen aus Mischungen von $\mathrm{H}_{2} \mathrm{O}, \mathrm{NH}_{3}$, und den einfachsten Kohlenwasserstoffen. Angew. Chem. 69:681

45. Sagan, C., Khare, B. N. 1971. Longwavelength ultraviolet photoproduction of amino acids on the primitive earth. Science 173:417-20

46. Ferris, J. P., Nicodem, D. E. 1974. $\mathrm{NH}_{3}$ : Did it have a central role in chemical evolution? In The Origin of Life and Evolutionary Biochemistry, ed. G. Deborin, K. Dose, S. Fox, M. Kritsky. New York: Plenum. In press

47. Hong, K., Hong, J., Becker, R. S. 1974. Chemical reactions of interest in chemical evolution and interstellar chemistry initiated by hot hydrogen atoms. Science 184:984-87

48. Elpiner, I. E. 1964. Ultrasound: Physical, Chemical, and Biological Effects. Transl. F. L. Sinclair. New York:Consultants Bur. $371 \mathrm{pp}$.

49. Anbar, M. 1968. Cavitation during impact of liquid water on water: geochemical implications. Science 161:1343-44 
50. Bar-Nun, A., Bar-Nun, N., Bauer, S. H., Sagan, C. 1970. Shock synthesis of amino acids in simulated primitive environments. Science 168:470-73

51. Abelson, P. H. 1966. Chemical events on the primitive earth. Proc. Nat. Acad. Sci. USA 55:1365-72

52. van Trump, J. E., Miller, S. L. 1973. Carbon monoxide on the primitive earth. Earth Planet. Sci. Lett. 20: 145-50

53. Anders, E., Hayatsu, R., Studier, M. H. 1973. Organic compounds in meteorites. Science 182:781-90

54. Hubbard, J. S., Hardy, J. P., Horowitz, N. H. 1971. Photocatalytic production of organic compounds from $\mathrm{CO}$ and $\mathrm{H}_{2} \mathrm{O}$ in a simulated Martian atmosphere. Proc. Nat. Acad. Sci. USA 68:574-48

55. Hubbard, J. S., Hardy, J. P., Voecks, G. E., Golub, E. E. 1973. Photocatalytic synthesis of organic compounds from $\mathrm{CO}$ and water: Involvement of surfaces in the formation and stabilization of products. J. Mol. Evol. 2:149-66

56. Tseng, S. S., Chang, S. 1974. Photoinduced free radicals on simulated Martian surface. Nature 248:575-77

57. Ferris, J. P., Williams, E. A., Nicodem, D. E., Hubbard, J. E., Voecks, G. E. 1974. Photolysis of $\mathrm{CO}-\mathrm{NH}_{3}$ mixtures and the Martian atmosphere. Nature 249:437-39

58. Bada, J. L., Miller, S. L. 1968. Ammonium ion concentration in the primitive ocean. Science 159:423-25

59. Ferris, J. P., Nicodem, D. E. 1972. Ammonia photolysis and the role of ammonia in chemical evolution. Nature 238:268-69

60. Lowe, C. U., Rees, M. W., Markham, R. 1963. Synthesis of complex organic compounds from simple precursors: formation of amino acids, amino-acid polymers, fatty acids and purines from ammonium cyanide. Nature 199: 219-22

61. Matthews, C. N. 1971. The origin of proteins: heteropolypeptides from hydrogen cyanide and water. See Ref. 19, pp. 231-35

62. Ferris, J. P., Donner, D. B., Lobo, A. P. 1973. Possible role of hydrogen cyanide in chemical evolution: investigation of the proposed direct synthesis of peptides from hydrogen cyanide. J. Mol. Biol. 74:499-510

63. Ferris, J. P., Donner, D. B., Lobo, A. P. 1973. Possible role of hydrogen cyanide in chemical evolution: the oligomeriza- tion and condensation of hydrogen cyanide. J. Mol. Biol. 74:511-18

64. Bernal, J. D. 1960. Reply to D. E. Hull. Nature 186:694-95

65. Paecht-Horowitz, M., Berger, J., Katchalsky, A. 1970. Prebiotic synthesis of polypeptides by heterogeneous polycondensation of amino-acid adenylates. Nature 228:636-39

66. Paecht-Horowitz, M., Katchalsky, A. 1973. Synthesis of amino acyladenylates under prebiotic conditions. J. Mol. Evol. 2:91-98

67. Degens, E. G., Matheja, J., Jackson, T. A. 1970. Template catalysis: asymmetric polymerization of amino-acids on clay minerals. Nature 227:492-93

68. Jackson, T. A. 1971. Preferential polymerization and adsorption of $\mathrm{L}$ optical isomers of amino acids relative to D-optical isomers on kaolinite templates. Chem. Geol. 7:295-306

69. Bonner, W. A., Flores, J. 1973. On the asymmetric adsorption of phenylalanine enantiomers by kaolin. Curr. Mod. Biol. 5:103-13

70. Bonner, W. A., Flores, J. J. 1973. Experiments on the Origins of Optical Activity. Presented at 4th Int. Conf. Origin of Life, Barcelona

71. Amariglio, A., Amariglio, H. 1971. Unsuccessful attempts of asymmetric synthesis under the influence of optically active quartz. Some comments about the possible origin of the dissymmetry of life. See Ref. 19, pp. 63-69

72. Wald, G. 1957. The origin of optical activity. Ann. NY Acad. Sci. 69:352-68

73. Horowitz, N. H., Miller, S. L. 1962. Current theories on the origin of life. Fortschr. Chem. Org. Naturst. 20: 423-59

74. Neuman, M. W., Neuman, W. F., Lane, K. 1970. On the possible role of crystals in the origins of life. III. The phosphorylation of adenosine to AMP by apatite. Curr. Mod. Biol. 3:253-59

75. Neuman, M. W., Neuman, W. F., Lane, K. 1970. On the possible role of crystals in the origins of life. IV. The phosphorylation of nucleotides. Curr. Mod. Biol. 3:277-83

76. Lohrmann, R., Orgel, L. E. 1971. Ureainorganic phosphate mixtures as prebiotic phosphorylating agents. Science 171:490-94

77. Bishop, M. J., Lohrmann, R., Orgel, L. E. 1972. Prebiotic phosphorylation of thymidine at $65^{\circ} \mathrm{C}$ in simulated desert conditions. Nature 237:162-64 
78. Österberg, R., Orgel, L. E., Lohrmann, R. 1973. Further studies of urea-catalyzed phosphorylation reactions. $J$. Mol. Evol. 2:231-34

79. Verlander, M. S., Lohrmann, R., Orgel, L. E. 1973. Catalysts for the self-polymerization of adenosine cyclic $2^{\prime}, 3^{\prime}$ phosphate. J. Mol. Evol. 2:303-16

80. Ósterberg, R., Orgel, L. E. 1972. Polyphosphate and trimetaphosphate formation under potentially prebiotic conditions. J. Mol. Evol. 1:241-48

81. Lundstrom, F. O., Whittaker, C. W. 1937. Chemical reactions in fertilizer mixtures. Ind. Eng. Chem. 29:61-68

82. Lohrmann, R. 1972. Formation of urea and guanidine by irradiation of ammonium cyanide. J. Mol. Evol. 1:263-69

83. Handschuh, G. J., Orgel, L. E. 1973. Struvite and prebiotic phosphorylation. Science 179:483-84

84. McConnell, D. 1973. Precipitation of phosphates in a primeval sea. Science 181:582

85. Handschuh, G. J., Orgel, L. E. 1973. Reply to McConnell. Science 181:582

86. Handschuh, G. J., Lohrmann, R., Orgel, L. E. 1973. The effect of $\mathrm{Mg}^{2+}$ and $\mathrm{Ca}^{2+}$ on urea-catalyzed phosphorylation reactions. J. Mol. Evol. 2:251-62

87. Fuller, W. D., Sanchez, R. A., Orgel, L. E. 1972. Studies in prebiotic synthesis. VI. Synthesis of purine nucleosides. J. Mol. Biol. 67:25-33

88. Fuller, W. D., Sanchez, R. A., Orgel, L. E. 1972. Studies in prebiotic synthesis. VII. Solid-state synthesis of purine nucleosides. J. Mol. Evol. 1:249-57

89. Lohrmann, R., Orgel, L. E. 1973. Prebiotic activation processes. NaAure 244: $418-20$

90. Weimann, B. J., Lohrmann, R., Orgel, L. E., Schneider-Bernloehr, H., Sulston, J. E. 1968. Template-directed synthesis with adenosine-5'-phosphorimidazolide. Science 161:387

91. Hayes, J. M. 1967. Organic constituents of meteorites-a review. Geochim. Cosmochim. Acta 31:1395-1440

92. Kvenvolden, $K$. et al 1970 . Evidence for extraterrestrial amino acids and hydrocarbons in the Murchison meteorite. Nature 228:923-26

93. Kvenvolden, K. A., Lawless, J. G., Ponnamperuma, C. 1971. Nonprotein amino acids in the Murchison meteorite. Proc. Nat. Acad. Sci. USA 68: 486-90

94. Oró, J., Gibert, J., Lichtenstein, H., Wikstrom, S., Flory, D. A. 1971.
Amino acids, aliphatic and aromatic hydrocarbons in the Murchison meteorite. Nature 230:105-6

95. Lawless, J. G., Kvenvolden, K. A., Peterson, E., Ponnamperuma, C., Moore, C. 1971. Amino acids indigenous to the Murray meteorite. Science 173:626-27

96. Cronin, J. R., Moore, C. B. 1971. Amino acid analyses of the Murchison, Murray, and Allende carbonaceous chondrites. Science 172:1327-29

97. Lawless, J. G., Kvenvolden, K. A., Peterson, E., Ponnamperuma, C., Jarosewich, E. 1972. Evidence for amino acids of extraterrestrial origin in the Orgueil meteorite. Nature 236:66-67

98. Becquerel, P. 1924. La vie terrestre provient-elle d'un autre monde? $L ' A s$ tronomie 38:393-417

99. Hayatsu, R. 1964. Orgueil meteorite: organic nitrogen contents. Science 146:1291-92

100. Folsome, C. E., Lawless, J., Romiez, M., Ponnamperuma, C. 1971. Heterocyclic compounds indigenous to the Murchison meteorite. Nature 232: 108-9

101. Rank, D. M., Townes, C. H., Welch, W. J. 1971. Interstellar molecules and dense clouds. Science 174:1083-1101

102. Buhl, D. 1971. Chemical constituents of interstellar clouds. Nature 234:332-34

103. Oró, J. 1972. Extraterrestrial organic analysis. Space Life Sci. 3:507-50

104. Miller, S. L. 1957. The formation of organic compounds on the primitive earth. Ann. NY Acad. Sci. 69:260-75

105. Sanchez, R. A., Ferris, J. P., Orgel, L. E. 1966. Cyanoacetylene in prebiotic synthesis. Science 154:784-85

106. Oró, J., Kimball, A. P. 1961. Synthesis of purines under possible primitive earth conditions. Arch. Biochem. Biophys. 94:217-27

107. Sanchez, R., Ferris, J., Orgel, L. E. 1966. Conditions for purine synthesis: Did prebiotic synthesis occur at low temperatures? Science 153:72-73

108. Ferris, J. P., Sanchez, R. A., Orgel, L. E. 1968. Studies in prebiotic synthesis. 3. Synthesis of pyrimidines from cyanoacetylene and cyanate. J. Mol. Biol. 33:693-704

109. Ring, D., Wolman, Y., Friedmann, N., Miller, S. L. 1972. Prebiotic synthesis of hydrophobic and protein amino acids. Proc. Nat. Acad. Sci. USA 69:765-68

110. Wolman, Y., Haverland, W. J., Miller, S. L. 1972. Nonprotein amino acids from spark discharges and their comparison with the Murchison meteorite 
amino acids. Proc. Nat. Acad. Sci. USA 69:809-11

111. Anders, E. 1971. Meteorites and the early solar system. Ann. Rev. Astron. Astrophys. 9:1-34

112. Sagan, $C$. Interstellar organic chemistry. 1972. Nature 238:77-80

113. Breger, I. A., Zubovic, P., Chandler, J. C., Clarke, R. S. 1972. Occurrence and significance of formaldehyde in the Allende carbonaceous chondrite. $\mathrm{Na}$ ture 236:155-58

114. Edsall, J. T., Wyman, J. 1958. Biophysical Chemistry, 23-25. New York: Academic. $699 \mathrm{pp}$.

115. Opp, A. G. 1974. Pioneer 10 mission: summary of scientific results from the encounter with Jupiter. Science 183: 302-3

116. Woeller, F., Ponnamperuma, C. 1969. Organic synthesis in a simulated Jovian atmosphere. Icarus 10:386-92

117. Sagan, C., Khare, B. N. 1971. Experimental Jovian photochemistry:Initial results. Astrophys. J. 168:563-69

118. Sagan, C. 1971. The solar system beyond Mars: An exobiological survey. Space Sci. Rev. 11:827-66

119. Lewis, J. S., Prinn, R. G. 1971. Chemistry and photochemistry of the atmosphere of Jupiter. Theory and Experiment in Exobiology 1:125-42

120. Hunten, D. M., Ed. 1974. The Atmosphere of Titan. Washington DC: Nat. Aeronaut. Space Admin. $177 \mathrm{pp}$.

121. Kliore, A., Cain, D. L., Fjeldbo, G., Seidel, B. L., Rasool, S. I. 1974. Preliminary results on the atmospheres of Io and Jupiter from the Pioneer 10 S-band occultation experiment. Science 183: 323-24

122. Various authors. 1972. The Viking missions to Mars. Icarus 16:1-227

123. Various authors. 1973. Scientific results of the Mariner 9 mission to Mars. J. Geophys. Res. 78:4007-4440

124. Ward, W. R. 1973. Large-scale variations in the obliquity of Mars. Science $181: 260-62$

125. Cutts, J. A. 1973. Nature and origin of layered deposits of the Martian polar regions. J. Geophys. Res. 78:4231-49

126. Sagan, C., Toon, O. B., Gierasch, P. J. 1973. Climatic change on Mars. Science 181:1045-49

127. Murray, B. C., Malin, M. C. 1973. Polar volatiles on Mars - theory versus observation. Science 182:437-43

128. Milton, D. J. 1973. Water and processes of degradation in the Martian landscape. J. Geophys. Res. 78:4037-47

129. Ingersoll, A. P. 1970. Mars: occurrence of liquid water. Science 168:972-73

130. Milton, D. J. 1974. Carbon dioxide hydrate and floods on Mars. Science 183:654-55

131. Barth, C. A. 1974. The atmosphere of Mars. Ann. Rev. Earth Planet. Sci. 2:333-67

132. McElroy, M. B. 1972. Mars: an evolving atmosphere. Science 175:443-45

133. Brinkmann, R. T. 1971. Mars: has nitrogen escaped? Science 174:944-45

134. Horowitz, N. H., Cameron, R. E., Hubbard, J. S. 1972. Microbiology of the dry valleys of Antarctica. Science 176: 242-45 


\section{CONTENTS}

Analysis of Genetic Regulatory Mechanisms, Jon Beckwith and Peter Rossow

Controlling Elements in Maize, $J . R$. S. Fincham and $G . R$. $K$. Sastry

The Relationship between Genes and Polytene Chromosome Bands, George Lefevre Jr.

Genetic Polymorphism of the Histocompatiallity-2 Loci of the MousE, Jan Klein

Biochemical Genetics of Bacteria, Joseph S. Gots and Charles E. Benson

Genetics of Amino Acid Transport in Bacteria, Yeheskel S. Halpern

Genetic and Antibiotic Modification of Protein Synthesis, David Schlessinger

On the Origin of RNA Tumor Viruses, Howard $M$. Temin

Pheromones as a Means of Genetic Control of Behavior, Jack E. Leonard, Lee Ehrman, and Anita Pruzan

Gene Expression in Somatic Cell Hybrids, Richard L. Davidson

Regulation: Positive Control, Ellis Englesberg and Gary Wilcox

Accessory Chromosomes, Arne Müntzing

Somatic Cell Genetics of Higher Plants, R. S. Chaleff and P. S. Carlson

Fungal Genetics, D. G. Catcheside

Genetics of DNA Tumor Viruses, Walter Eckhart

Frameshift Mutations, John R. Roth

Genetic Analysis of the Chloroplast and Mitochondrial

GeNOMES, Nicholas $\boldsymbol{W}$. Gillham

The Origin of Life, $N$. H. Horowitz and Jerry S. Hubbard

Gene Control of Mammalian Differentiation, Beatrice Mintz

\section{INDEXES}

Subject INDEX 